\title{
Influência do Teor de Mo na Microestrutura de Ligas Fe-9Cr-xMo
}

\author{
(Effect of the Content of Molybdenum in the Microstructure of Fe-9Cr-xMo Alloy)
}

\begin{abstract}
Rodrigo Freitas Guimarães ${ }^{1}$, Nathália Cândido Figueiredo², Victor Moita Pinheiro², Hélio Cordeiro de Miranda², Hamilton Ferreira Gomes de Abreu ${ }^{2}$

${ }^{1}$ Instituto Federal de Educação, Ciência e Tecnologia do estado do Ceará, Área da indústria/Núcleo de pesquisa em inovação de automação industrial, Fortaleza, Ceará, Brasil rodrigofg@ifce.edu.br

${ }^{2}$ Universidade Federal do Ceará, Departamento de Engenharia Metalúrgica e de Materiais/ Laboratório de Engenharia de Soldagem, Fortaleza, Ceará,Brasil, nc.figueiredo@metalmat.ufc.br, victormp@fisica.ufc.br, hmiranda@ufc.br, hamilton@ufc.br.
\end{abstract}

\section{Resumo}

Aços Cr-Mo são usados na indústria do petróleo em aplicações com óleos crus ricos em compostos sulfurosos. Aços comerciais como 2.5CrlMo ou 9CrlMo têm se mostrado ineficientes em consequência de altos índices de corrosão naftênica. Uma estratégia para resolver este problema é o aumento do teor de molibdênio destes aços. Neste trabalho foi estudado o efeito do aumento do teor de molibdênio na microestrutura de ligas Fe-9Cr-xMo, solubilizadas e soldadas. Foram levantados os diagramas de fases com auxílio de um programa comercial para verificar as possiveis fases a serem formadas e identificar os problemas de soldagem. A microestrutura das ligas solubilizadas foi analisada por microscopia óptica e EBSD, além da medição da dureza. Foram realizadas soldagens autógenas para verificar o efeito do aporte térmico na microestrutura e na dureza das ligas. O aumento do teor de molibdênio resultou no aumento da dureza das ligas. A análise microestrutural das ligas soldadas apresentou uma particularidade para a liga com menor teor de molibdênio, a presença de martensita. Já as ligas com maior teor de molibdênio apresentaram uma microestrutura completamente ferrítica. A formação de martensita pode ser um problema na solda da liga com menor teor de molibdênio, uma vez que a mesma pode causar perdas nas propriedades mecânicas comprometendo sua aplicação.

Palavras-chave: Aços Inoxidáveis Ferríticos; Soldagem; Diagrama de Fase; Molibdênio.

Abstract: Cr-Mo steels are used in the petroleum industry in applications with crude oils rich in sulfur compounds. 2.5Cr1Mo or 9Cr1Mo do not resist to operating conditions when in contact with crude oils. The increasing of molybdenum content can improve the corrosion resistance of these alloys. This paper studied the effect of increased concentration of molybdenum in the microstructure of Fe$9 \mathrm{Cr}$-xMo alloys, annealed and welded. Phase diagrams were built with the aid of commercial program to check the possible phases to be formed and to identify the problems of welding. Analyses were realized by optical microscopy, EBSD and hardness tests. Autogenous welds were carried out to verify the effect of heat input on microstructure and hardness of the alloys. The results indicated that the increase in molybdenum concentration resulted in increased hardness of the alloys. After welding the alloy with lower molybdenum content presented the formation of martensite. Alloys with molybdenum content above $5 \%$ presented a fully ferritic microstructure. The formation of martensite can be a problem in weld alloys with lower content of molybdenum, since it can cause loss in mechanical properties hindering their application.

Key-words: Ferritic Stainless Steel; Welding; Phases Diagram; Molibdenum.

\section{Introdução}

Aços Cr-Mo têm sido usados na indústria do petróleo principalmente em aplicações que envolvem o contato com óleos crus ricos em compostos sulfurosos. A busca por petróleos em altas profundidades e a maturidade dos poços produtores tem cada vez mais aumentado a acidez do petróleo a ser refinado. Aços comerciais como $2.5 \mathrm{Cr} 1 \mathrm{Mo}$ ou $9 \mathrm{Cr} 1 \mathrm{Mo}$ - respectivamente

(Recebido em 19/02/2010; Texto final em 19/09/2010).

Artigo originalmente publicado no CONSOLDA 2009,

Piracicaba, SP, Outubro de 2009.
P3 e P9 segundo o código ASME IX - têm se mostrado ineficientes em consequência de altos índices de corrosão naftênica. Para enfrentar este problema duas estratégias têm sido adotadas pelas empresas produtoras de petróleo: controle por sequestrante de $\mathrm{H}_{2} \mathrm{~S}$ e uso de metalurgia especial. Dentro desta segunda estratégia uma das ações seria o aumento do teor de Mo nos aços [1].

O molibdênio aumenta a resistência do material a atmosferas ácidas não oxidantes, à corrosão localizada e a resistência a altas temperaturas [2-6].

$\mathrm{O}$ aumento do teor de molibdênio até $7 \%$ em peso nos aços inoxidáveis austeníticos foi estudado por $\mathrm{Wu}$ et al [7]. Eles concluíram que o molibdênio melhora sensivelmente a resistência à corrosão naftênica nestes aços. Esta melhora se 
deve, entre outros fatores, ao aumento da resistência à corrosão por pites devido à melhoria na microestrutura e na dureza.

O molibdênio atua na formação de uma microestrutura ferrítica, assim como o cromo. O aumento nos teores de molibdênio, além de proporcionar um aumento da resistência mecânica e elevar a dureza do aço, favorece a formação de precipitados intermetálicos do tipo sigma ( ), chi (c) e mu (m), o que prejudica a soldabilidade dos mesmos devido a perda de ductilidade. Estas fases podem surgir em temperaturas entre 600 ${ }^{\circ} \mathrm{C}$ e $900{ }^{\circ} \mathrm{C}$, sendo a sua formação muito lenta, necessitando de horas para ocorrer. Uma vez que estas fases são difusionais, observadas em condições de equilíbrio através de diagrama de fases, após tratamento térmico ou soldagem, são necessárias altas taxas de resfriamento para evitar a formação destes precipitados [4, 7-9].

A fase sigma é um composto intermetálico, de composição nominal Fe-Cr e célula unitária tetragonal, que é duro (equivalente em alguns casos a $940 \mathrm{HV}$ ou $68 \mathrm{HRC}$ ) e não magnético. A fase chi (c), por sua vez, possui estrutura cúbica ordenada, com composição $\mathrm{Fe}-25 \% \mathrm{Cr}-2 \% \mathrm{Ni}-15-20 \% \mathrm{Mo}-1 \% \mathrm{Mn}$. Tanto a fase chi (c) como a sigma (s) são frágeis e indesejáveis num aço inoxidável pois comprometem tanto a tenacidade quanto a resistência à corrosão [10-13]. Estudos recentes têm mostrado que a formação da fase chi (c) ocorre antes da fase sigma (s), onde a fase chi (c) atua como um núcleo para a formação da fase sigma (s) [14].

A fase mu (m) é um composto intermetálico duro e frágil que pode aparecer em materiais compostos por ferro, níquel ou cobalto ligados a metais refratários, como o nióbio, tântalo, molibdênio e tungstênio. Esta fase apresenta uma estrutura cristalina hexagonal e possui fórmula nominal $\mathrm{Fe}_{7} \mathrm{Mo}_{6}$, considerando o sistema Fe-Mo. Essa fase é prejudicial aos materiais, pois a sua precipitação ocasiona um empobrecimento desses elementos de liga na matriz, adicionalmente, sua forma agulhada funciona como um concentrador de tensões, facilitando a propagação de trincas $[15,16]$. A formação da fase um pode levar até $12 \mathrm{~h}$ a uma temperatura de $1000{ }^{\circ} \mathrm{C}$ [17].

As fases intermetálicas podem ser classificadas em dois tipos: fases topologicamente compactas (TCP) e fases geometricamente compactas (GCP). As fases TCP são caracterizadas pela presença de camadas fechadas separadas por uma distância interatômica relativamente elevada. As fases chi, sigma e mu são típicas TCP [18].

As ligas comerciais tipo P3 e P9 são utilizadas na indústria do petróleo, tanto na condição temperada e revenida quanto normalizada. A submissão de ligas com baixos teores de molibdênio a altas termperaturas pode favorece a formação da fase austenítica que, por sua vez, quando resfriada rapidamente, transforma-se em martensita, como é o caso da soldagem [1].

Neste contexto, é interessante estudar ligas 9Cr-xMo de forma que o percentual de molibdênio favoreça uma estrutura cúbica de corpo centrado (CCC) em qualquer temperatura não permitindo a transformação para austenita. Contudo, este alto teor de molibdênio pode favorecer a formação das fases intermetálicas já citadas.

Uma vez que não existem informações sobre a característica microestrutural de ligas ferríticas com alto teor de molibdênio, neste trabalho foi estudado efeito do aumento do teor de molibdênio na microestrutura de ligas Fe-9Cr-xMo (onde $\mathrm{x}$ assume valores de 5, 7 e 9), nas condições solubilizada e soldada, afim de verificar se há ou não a formação de outras fases além da fase ferrítica. Para isso, foram construídos os diagramas de equilíbrio e fases presentes com auxílio de um programa termodinâmico computacional. Em seguida, foram realizadas microscopias ópticas e eletrônicas, além do levantamento dos perfis de microdureza Vickers ao longo da ZAC.

\section{Materiais e Métodos}

Três composições com diferentes teores de molibdênio, conforme mostrado na Tabela 1 foram denominadas E1, E2 e E3. Estas ligas foram fundidas em forno de indução, laminadas a quente, onde a temperatura de início de laminação foi de 1000 ${ }^{\circ} \mathrm{C}$.

Tabela 1. Composição química (\% em massa) das ligas Fe-Cr.

\begin{tabular}{|c|c|c|c|c|c|}
\hline Liga & $\mathrm{C}$ & $\mathrm{Mn}$ & $\mathrm{Si}$ & $\mathrm{Cr}$ & Mo \\
\hline E1 & 0,030 & 0,37 & 0,34 & 9,5 & 5,3 \\
\hline E2 & 0,031 & 0,38 & 0,37 & 9,5 & 7,3 \\
\hline E3 & 0,041 & 0,41 & 0,45 & 9,6 & 9,3 \\
\hline
\end{tabular}

Utilizando um programa computacional termodinâmico, Thermocalc, foram levantados diagramas de fases com base nos teores de cromo e molibdênio das ligas apresentadas na Tabela 1 , identificando as fases e determinando os tratamentos térmicos que favoreçam a sua soldagem.

Amostras das ligas submetidas aos tratamentos térmicos foram caracterizadas através de exames metalográficos por microscopia ótica (MO) e realização de ensaio de microdureza, sendo realizadas 7 (sete) medidas ao todo, descartando o maior e o menor valor medido. Para a realização das análises microestruturais, as amostras foram atacadas com reagente Vilella [19].

Foram realizadas soldagens pelo processo TIG autógeno na posição plana, com eletrodo toriado de $2,4 \mathrm{~mm}$ de diâmetro em corrente contínua, eletrodo negativo (CCEN), utilizando argônio (Ar) como gás de proteção (vazão de gás de $14 \mathrm{~L} / \mathrm{min}$ ), sobre chapas com dimensões de $10,00 \mathrm{~mm}$ x 40,00 mm x 80,00 mm. A deposição dos cordões de solda foi realizada empregando uma velocidade de soldagem de $25,4 \mathrm{~cm} / \mathrm{min}$, corrente de $200 \mathrm{~A}$ e tensão de $17 \mathrm{~V}$, resultando em um aporte térmico de $8 \mathrm{~kJ} / \mathrm{cm}$.

As amostras soldadas passaram pela caracterização das regiões da solda e do metal de base através de exames metalográficos, por microscopia ótica (MO) e por análise de difração de elétrons retro espalhados (EBSD) para caracterizar a presença de possíveis fases precipitadas. Foram ainda realizados ensaios de dureza Vickers visando levantar um perfil das propriedades mecânicas das ligas estudadas. 


\section{Resultados e Discussão}

\subsection{Estudo Termodinâmico do Sistema Fe-Cr-Mo}

Na Figura 1 tem-se o diagrama de equilíbrio do sistema Fe-Cr, sem a adição de molibdênio, onde pode-se observar, a presença do campo austenítico, a possibilidade da formação da fase sigma ( ) e, ainda, a estrutura ferrítica característica destes materiais. De acordo com Bhadeshia [20], a solubilidade do cromo no ferro gama ( $\mathrm{Fe}-$ ), estrutura cúbica de face centrada (CFC), é cerca de $13 \%$, mostrando que o valor obtido no diagrama da Figura 1, de 12,3\%, está coerente.

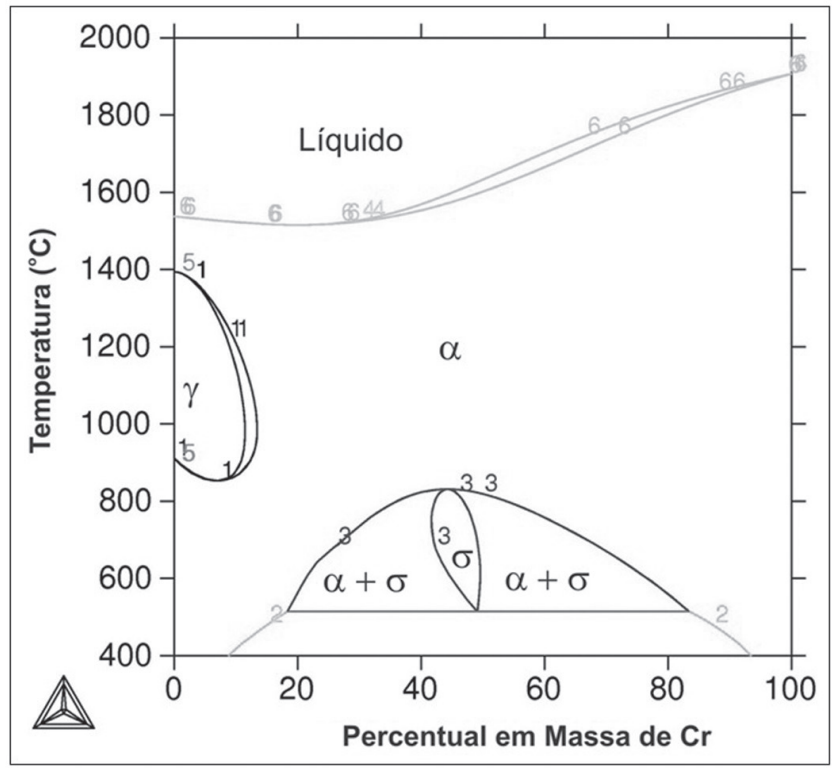

Figura 1. Diagrama de fases, sistema Fe-Cr.

Com a adição de molibdênio o diagrama $\mathrm{Fe}-\mathrm{Cr}$ é alterado, como está mostrado na Figura 2, reduzindo e até suprimindo a

a)

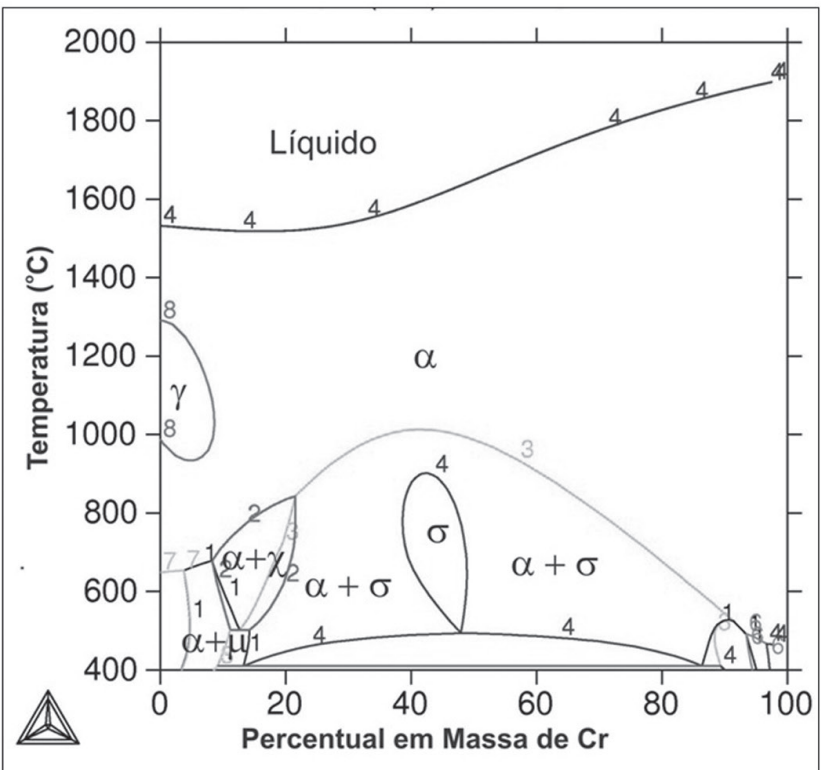

b)

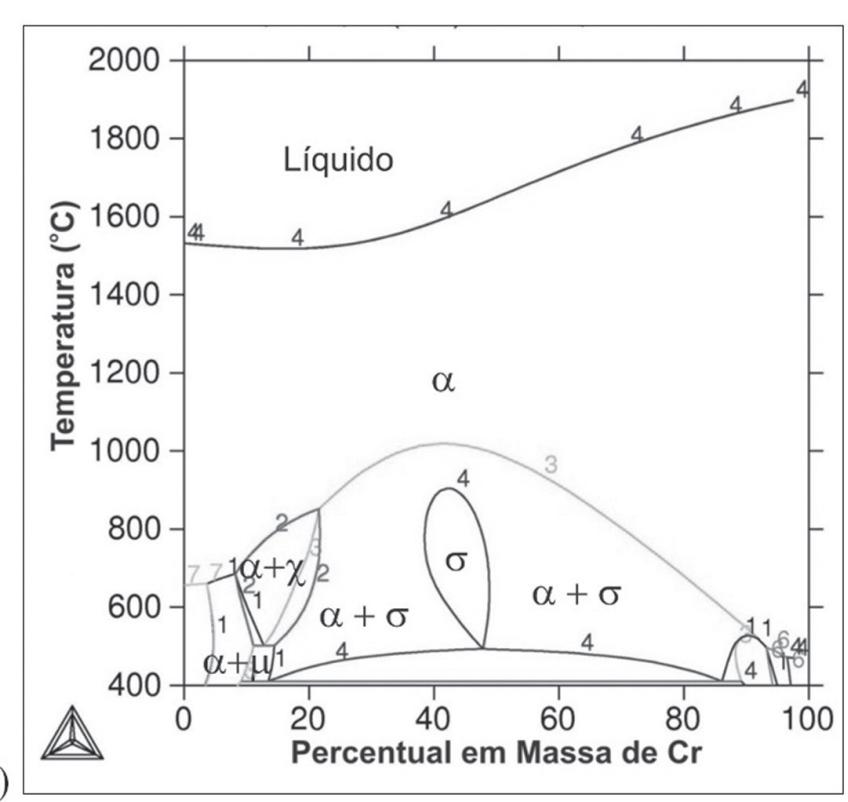

região da austenita $(\mathrm{g})$. Este comportamento já era esperado uma vez que o molibdênio é um elemento ferritizante $[4,5]$. O campo austenítico, de acordo com os diagramas plotados, é totalmente eliminado para teores de molibdênio superiores a 2,4\% (Figura $2 \mathrm{a}$ e Figura $2 \mathrm{~b}$ ) nas condições estudadas.

Apesar do aumento do teor de molibdênio favorecer a redução do campo austenítico, tornando a liga totalmente ferrítica para molibdênio maior que $2,4 \%$, ele possibilita a formação de fases precipitadas chi (c), mu (m) e sigma ( ), aumentando a fração destas fases com o aumento do molibdênio (Figura 3a). Estas fases são altamente prejudiciais uma vez que a precipitação das mesmas é acompanhada por um aumento de dureza e intensa perda de ductilidade, tenacidade e resistência a corrosão [10-13].

$\mathrm{Na}$ Figura $3 \mathrm{~b}$ é possível observar, abaixo de $410^{\circ} \mathrm{C}$, a formação da fase a', mas ao contrário do observado para a precipitação das fases intermetálicas citadas anteriormente e para a fase austenítica, o aumento do teor de molibdênio aparentemente não influencia a faixa de existência desta fase. A fase a' é rica em cromo e resulta no endurecimento e fragilização do aço [13].

A fim de melhor caracterizar as possíveis fases presentes nas ligas E1, E2 e E3 foram levantados os diagramas de fases com base nos elementos presentes (Tabela 1). Como está mostrado na Figura 4 é possível verificar que as ligas estudadas, dependendo das condições de temperatura a que sejam submetidas, poderão exibir a presença das fases chi c), mu (m) e sigma (s). De acordo com a Figura 4 a fase chi (c) é formada antes das fases mu (m), e sigma (s), conforme já havia sido observado por Park [14], observa-se ainda a presença da fase ferrítica, característica destas ligas. Verifica-se também a possibilidade de formação de carbonetos do tipo $\mathrm{M}_{6} \mathrm{C}$ e $\mathrm{M}_{23} \mathrm{C}_{6}$ para as três ligas, além da presença da fase austenítica para a liga com menor teor de molibdênio (E1, Figura 4a), o que não acontece para as liga E2 e E3 (Figura 4b e Figura 4c). É importante ressaltar que havendo a austenitização da liga E1, um resfriamento rápido poderá resultar na formação da fase martensítica, que pode ser prejudicial às propriedades do material.

Figura 2. Diagrama de fases para o sistema Fe-Cr. a) Com 2,4\% de molibdênio. b) Com 2,5\% de molibdênio. 

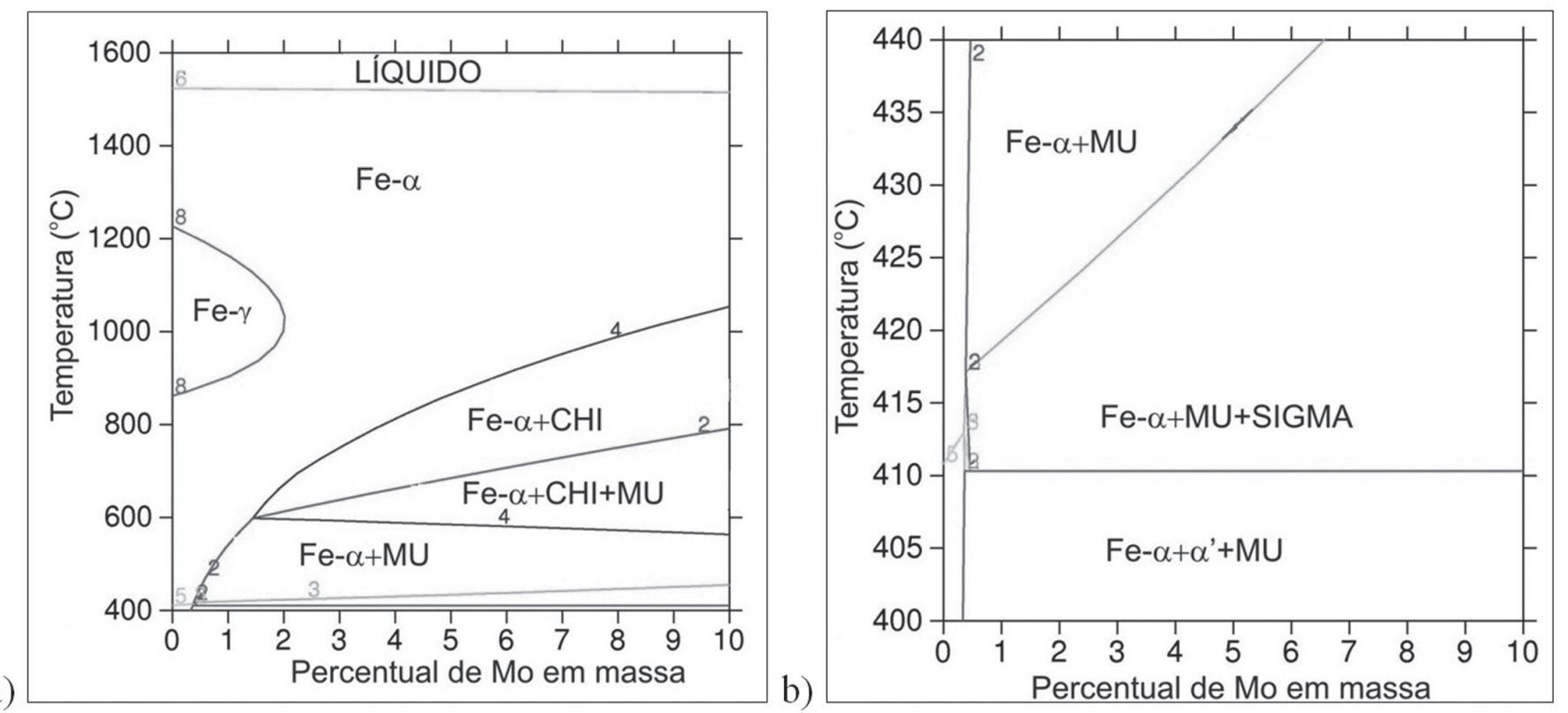

Figura 3. a) Diagrama de fases com variação do teor de molibdênio, considerando 9,5\% de cromo. b) Aumento no diagrama de fases da Figura 3a, mostrando a presença da fase '.

Analisando as ligas E1, E2 e E3 considerando um resfriamento a partir da temperatura de existência da fase líquida, tem-se o aparecimento da fase ferrítica. Continuando o resfriamento observa-se o aparecimento da fase chi (c), mu (m) e sigma (s) junto com a fase ferrítica, observado em todas as ligas estudadas.

$\mathrm{O}$ aumento dos teores de molibdênio favorece o surgimento da fase mu (m), sendo observado, o aparecimento de uma faixa de temperatura com a presença da fase ferrítica, chi (c) e mu (m), seguido de uma faixa de temperatura com a fase ferrítica e mu (m) e só depois é que se verifica a formação das fases ferrítica, $\mathrm{mu}(\mathrm{m})$ e sigma (s).

A formação das fases intermetálicas observadas fragilizam os aços, devendo ser, na medida do possível, evitadas. Tratamentos termomecânicos podem ser realizados para atingir-se uma condição de meta-estabilidade, visto que estas fases se formam por difusão e esta é função da temperatura e do tempo. Assim resfriamentos bruscos podem tornar a difusividade tão baixa que o estado de equilíbrio nunca, ou quase nunca seja atingido. As temperaturas de solubilização foram obtidas através dos diagramas da Figura 4, onde foi considerada a temperatura acima da qual só existisse a fase ferrítica. Na Tabela 2 são mostradas as temperaturas de solubilização das ligas estudadas. Tanto na Tabela 2 quanto na Figura 4 verifica-se que com o aumento do teor de molibdênio há um aumento na temperatura de solubilização. A liga E1, com menor teor de molibdênio, possui menor temperatura de solubilização e a liga E3, maior teor de molibdênio, apresenta a maior temperatura de solubilização.

\subsection{Caracterização microestrutural das ligas solubilizadas}

Na Figura 5 é apresentada a microscopia ótica da seção transversal das chapas correspondentes às ligas E1, E2 e E3, após a realização da solubilização de acordo com as temperaturas apresentadas na Tabela 2.
Tabela 2. Temperatura de solubilização $\left({ }^{\circ} \mathrm{C}\right)$ das ligas E1, E2 e E3

\begin{tabular}{|c|c|c|c|}
\hline Liga & Cr & Mo & $\mathrm{T}_{\text {sol }}{ }^{(1)}$ \\
\hline E1 & 9,5 & 5,3 & 1050 \\
\hline E2 & 9,5 & 7,3 & 1100 \\
\hline E3 & 9,6 & 9,3 & 1190 \\
\hline \multicolumn{4}{|c|}{${ }^{(1)} \mathrm{T}_{\text {sol }}-$ Temperatura de solubilização. }
\end{tabular}

Como pode ser verificado na Figura 5, tem-se uma microestrutura característica das ligas, do tipo ferrítica e, ainda, a presença de alguns pequenos precipitados, provavelmente formados devido à presença de carbono presentes nestas ligas. A microestrutura obtida após as solubilizações confirma os resultados dos diagramas levantados com o uso do programa, indicando que para os teores de cromo e molibdênio das ligas estudadas deveria apresentar uma estrutura cúbica de corpo centrado (CCC). Pelas micrografias da Figura 5, não foi verificado a formação das fases indesejáveis identificadas nos diagramas da Figura 4, possivelmente por terem uma cinética, onde necessitam de um certo tempo e uma dada temperatura para haver a precipitação e uma vez que optou-se por um resfriamento rápido, minimizou-se a possibilidade de formação das mesmas.

Os valores de microdureza Vickers das amostras das ligas E1, E2 e E3, laminadas a quente e solubilizadas, estão mostrados na Figura 6. Neste gráfico o valor médio das durezas medidas para cada liga e as barras horizontais indicam o valor máximo e o mínimo, medidos.

Como pode ser observado, o valor de dureza aumenta com o aumento do teor de molibdênio, confirmando o apresentado na literatura [3-5]. Verifica-se que as ligas estudadas apresenta um valor de dureza superior quando comparado com o aço ferrítico 9Cr-1Mo, de $178 \mathrm{HV}$ [21]. 
a)
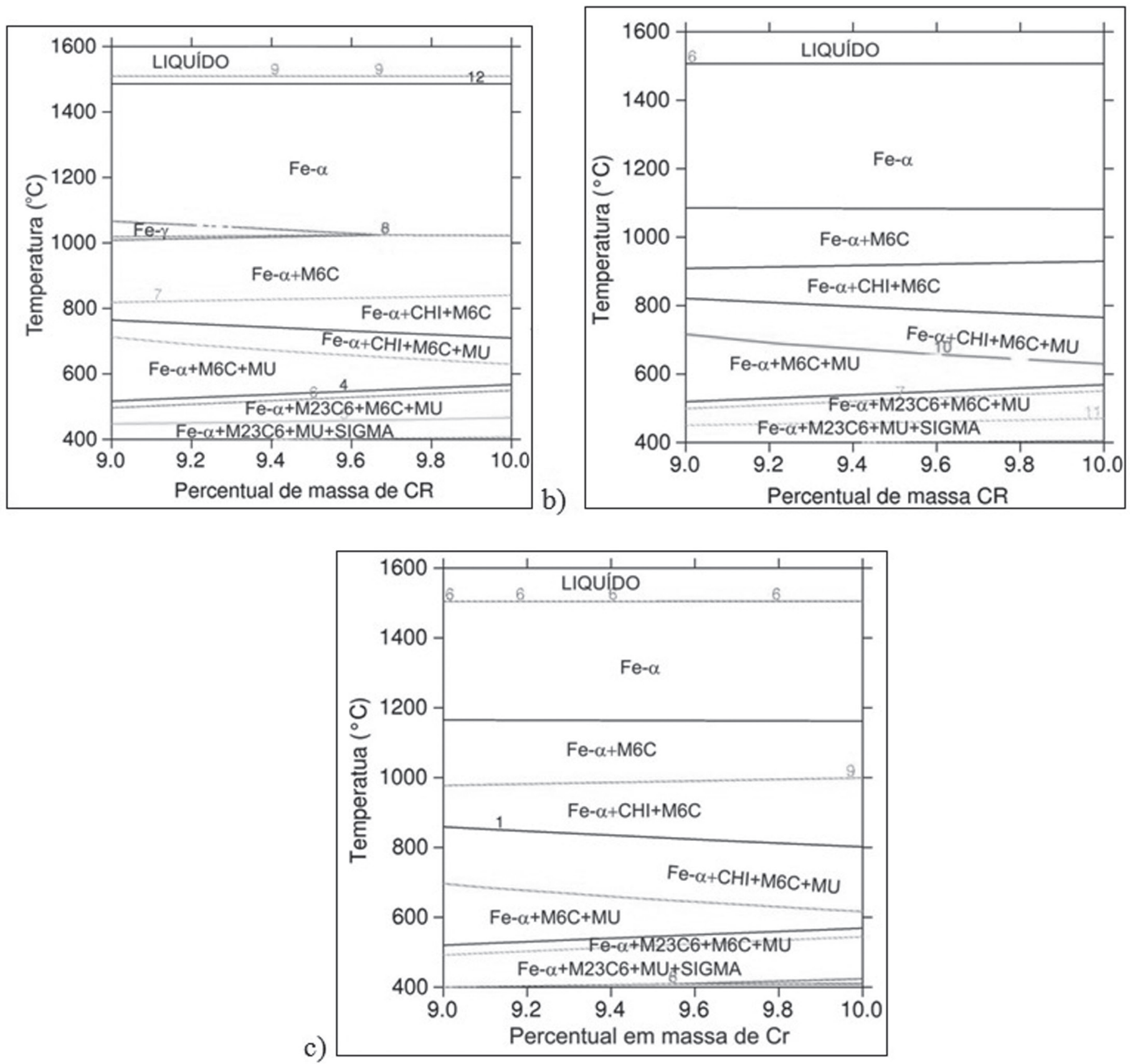

Figura 4. Diagrama de fases. a) Liga E1 (9,5Cr-5,3Mo). b) Liga E2 (9,5Cr-7,3 Mo). c) Liga E3 (9,6Cr-9,3 Mo).

\subsection{Soldagem Autógena}

A ZAC e o metal de solda (MS) da liga E1 são apresentados na Figura $7 \mathrm{a}$ e na Figura $7 \mathrm{~b}$. Nestas figuras, observa-se uma microestrutura ferrítica tanto para o MS quanto para a ZAC. Tem-se a presença de regiões escuras formadas ao longo dos contornos de grão de algumas regiões da ZAC. O aspecto destes contornos pode ser melhor observados na Figura 7c. De acordo com o diagrama da Figura 4a, a liga E1 pode apresentar a formação da fase chi (c), mu (m) e sigma ( ). A formação destas fases é favorecida pelo aumento nos teores molibdênio e também pela difusividade desta fase. Assim, a formação das mesmas seria mais favorável para as ligas E2 $(9,5 \% \mathrm{Cr}$ e $7,3 \% \mathrm{Mo})$ e E3 (9,6\% Cr e 9,3\% Mo) do que para E1 (9,5\% Cr e 5,3\% Mo), já que as ligas E2 e E3têm maior teor de Mo. As soldagens foram realizadas sem controle de preaquecimento favorecendo um resfriamento rápido, minimizando a possibilidade de formação destas fases uma vez que as mesmas são do tipo difusional.

Uma possibilidade para identificar essa fase é considerar a formação da martensita, uma vez que a liga E1 pode ter a presença de austenita (Figura 4a), o resfriamento rápido após a soldagem favorece a transformação martensítica.

Silva [22] verificou a formação de martensita, com morfologia semelhante à apresentada na Figura 7c), no aço ferrítico AISI 
(a)

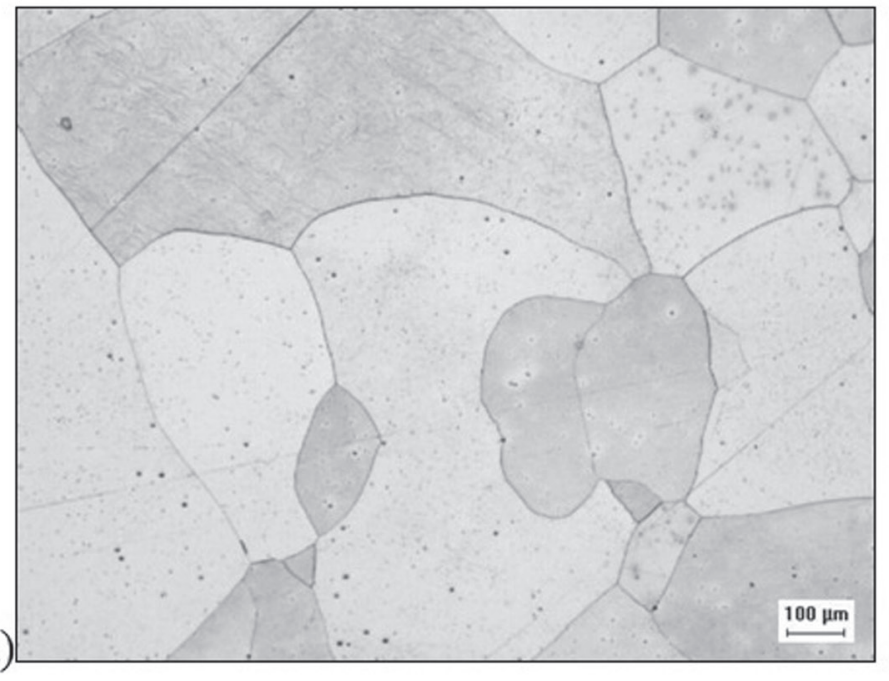

(b)
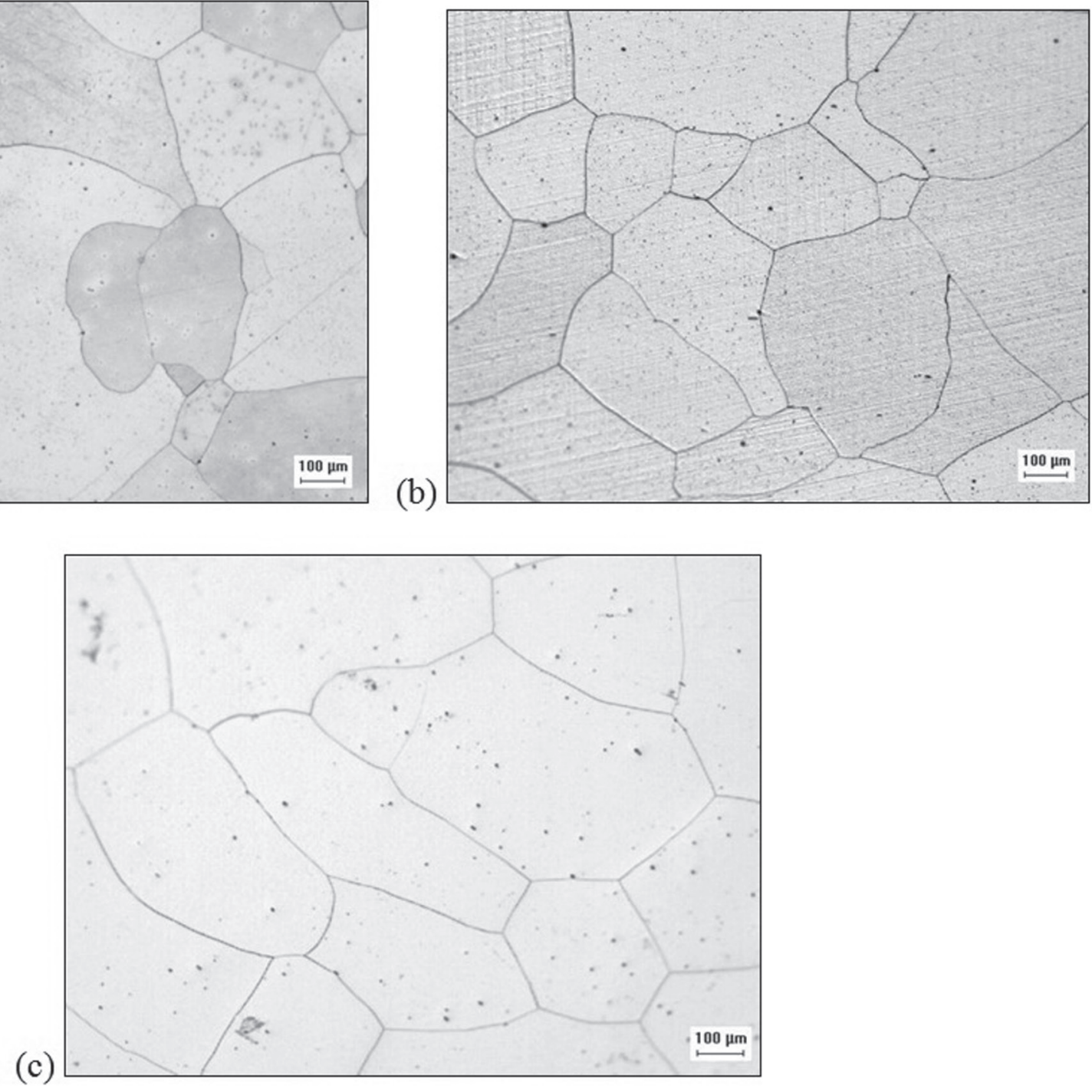

Figura 5. Microscopia ótica das ligas após laminação a quente e solubilização. Ataque: Vilella. Aumento 100X. a) Liga E1. b) Liga E2. c) Liga E3.

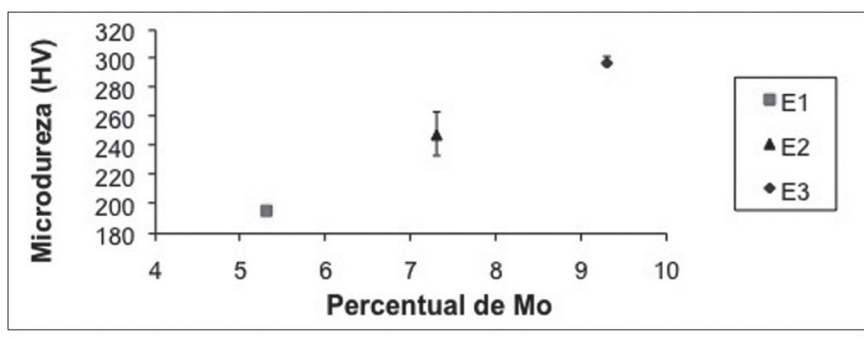

Figura 6. Microdureza das ligas E1, E2 e E3 na condição solubilizada.

410S submetido à soldagem com eletrodo revestido empregando diferentes aportes térmicos.

Para tentar confirmar a presença da martensita foram realizadas análises por EBSD na amostra soldada da liga E1, conforme está mostrado na Figura 8 e na Tabela 3. Através do EBSD é possível verificar que, além do Fe- (área clara na Figura 8), há a presença da fase martensita nos precipitados (área escura na Figura 8) observados na solda da liga E1.
$\mathrm{Na}$ tentativa de evidenciar a presença da martensita, a liga E1 soldada foi submetida a um novo reagente (Rigsbee and Vander Arend) [19] específico para revelação desta fase, cujo aspecto está mostrado na Figura 9. Este resultado é mais uma evidência da formação de martensita após a solda da liga E1.

Foram realizadas análises por MEV e EDX tanto nos precipitados quanto a matriz da liga E1 (Figura 10 e Figura 11). Como pode ser visto na Figura 10 observa-se uma microestrutura típica da martensita em placas. O EDX apresentado na Figura 11 mostra que não há diferença na composição química entre o precipitado observado e a matriz do material.

Tabela 3. Percentual das fases identificadas através do EBSD da Figura 8.

\begin{tabular}{|c|c|}
\hline Fase & $\%$ \\
\hline Não Identificada & 3,2 \\
\hline Ferro alfa (área clara) & 78,6 \\
\hline Martensita (área escura) & 18,2 \\
\hline
\end{tabular}


a)
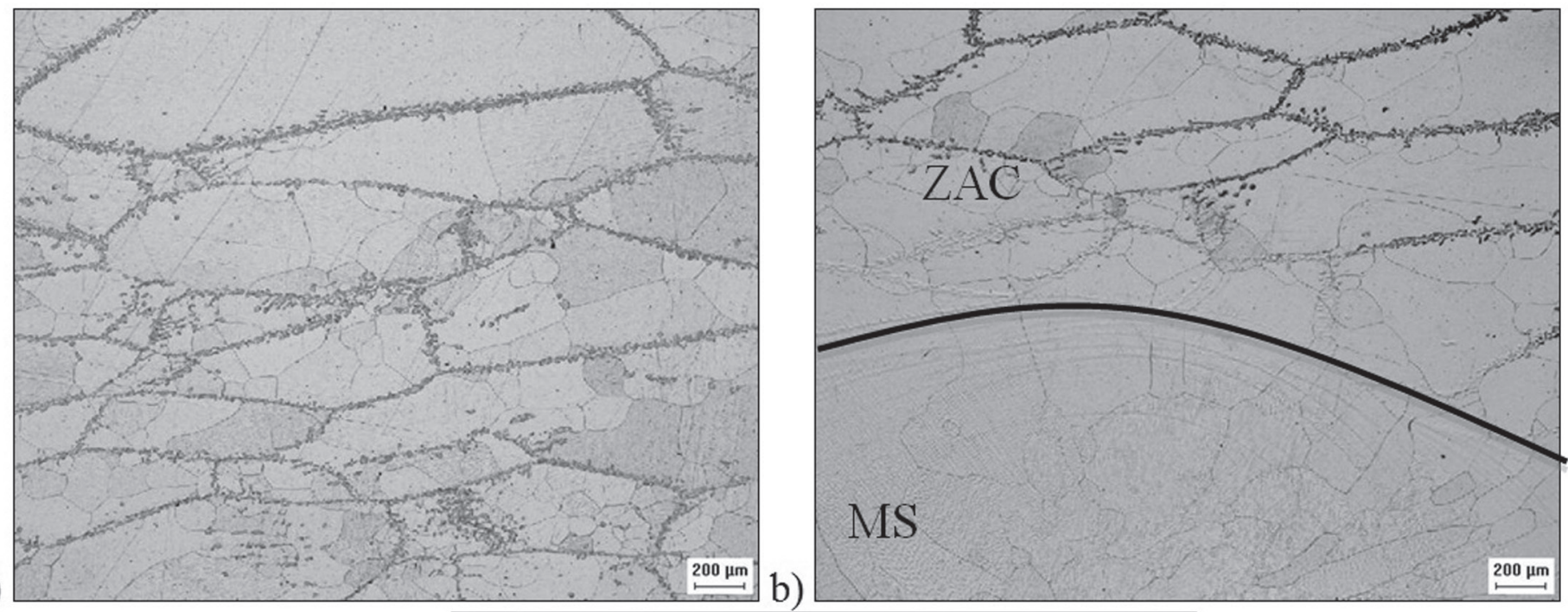

c)

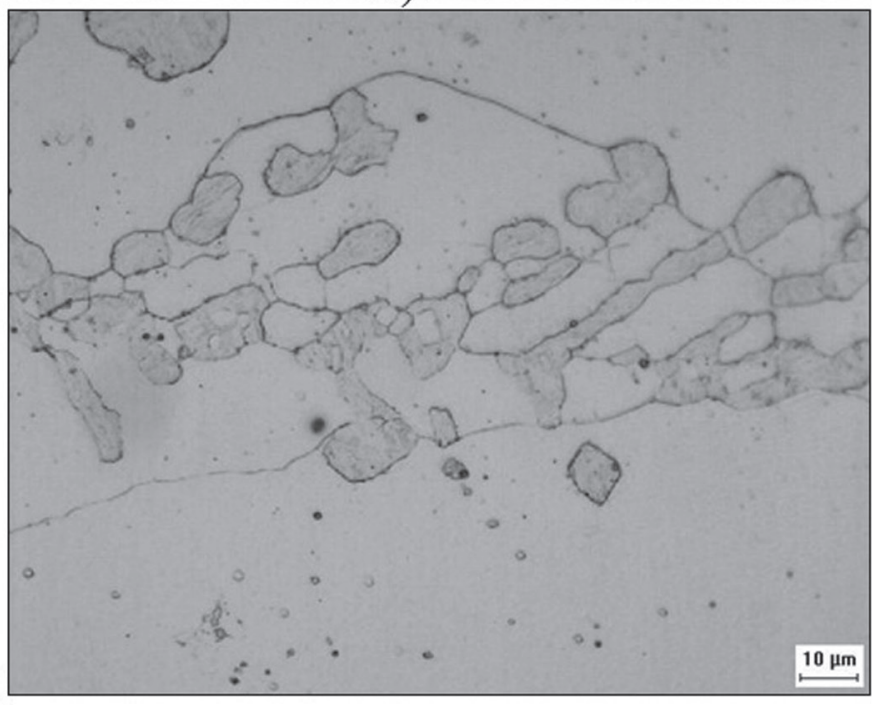

Figura 7. Micrografia da liga E1 após soldagem autógena. Ataque: Vilella. a) Zona afetada pelo calor da solda (ZAC), aumento 50X. b) Metal de solda (MS), aumento 50X. c) Precipitados formados nas regiões da ZAC, aumento 1000X.

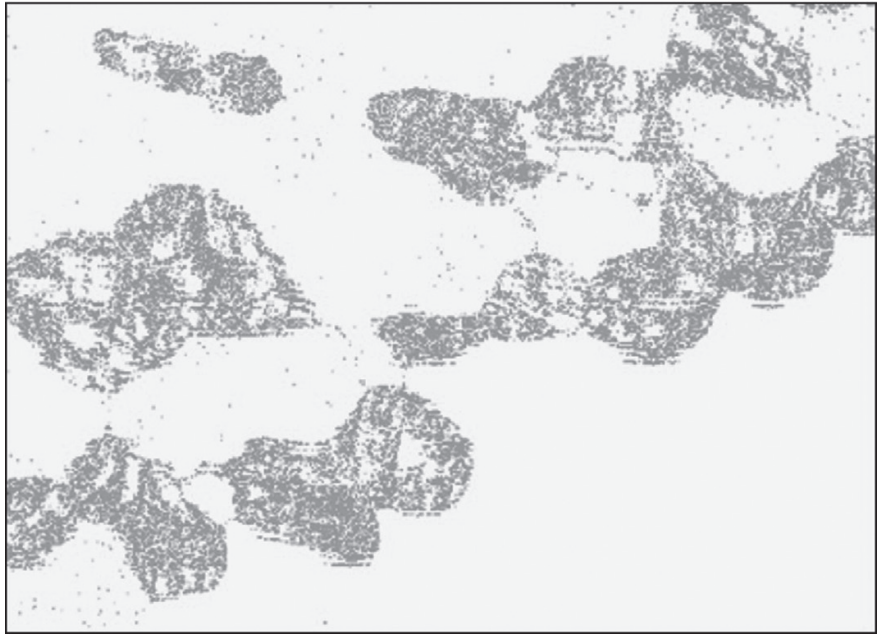

Figura 8. EBSD da liga E1, aumento de $4000 \mathrm{x}$.
Na Figura 12 e na Figura 13 tem-se a ZAC e o metal de solda das ligas E2 e E3, respectivamente, onde se percebe uma microestrutura ferrítica de grãos grandes na ZAC e a presença de alguns pequenos precipitados distribuídos ao longo da matriz dos grãos. Estes pequenos precipitados provavelmente são carbonetos, já observados nas ligas E2 e E3 na condição solubilizada (Figura 5) O aspecto destes contornos pode ser melhor observado na Figura 12c e na Figura 13c. Diferente da liga $\mathrm{E} 1$, não houve a formação de precipitados nos contornos de grão na ZAC das ligas E2 e E3. O maior teor de molibdênio das ligas E2 e E3, em comparação com a liga E1, torna mais favorável a formação das fases intermetálicas difusionais para as ligas E2 e E3 do que para a liga E1. Uma vez que não foi observada a presença de fases precipitadas nos contornos das ligas E2 e E3, tem-se mais uma evidência de que a fase formada após a soldagem da liga E1 não é uma fase difusional e sim a martensita. 
a)

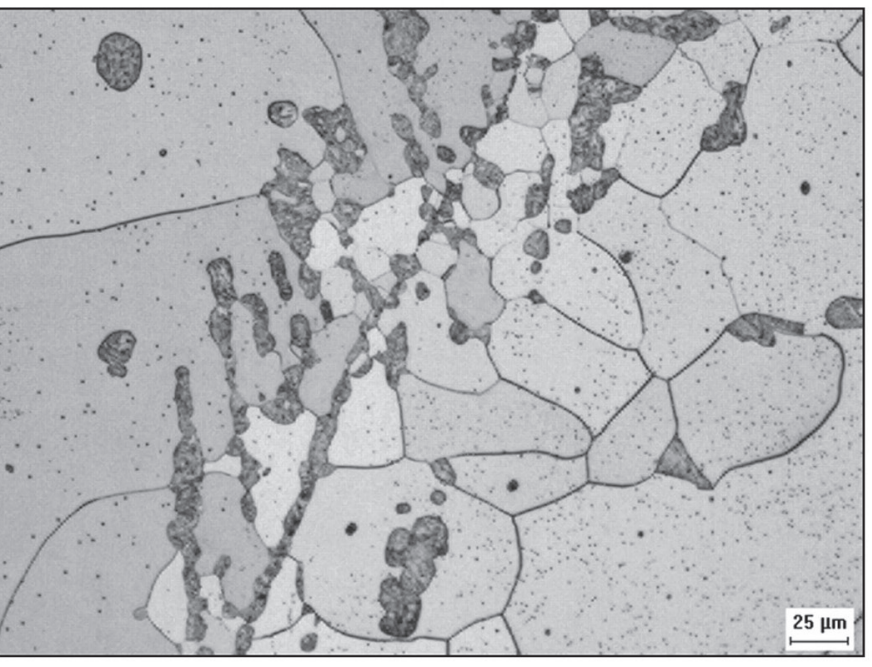

b)

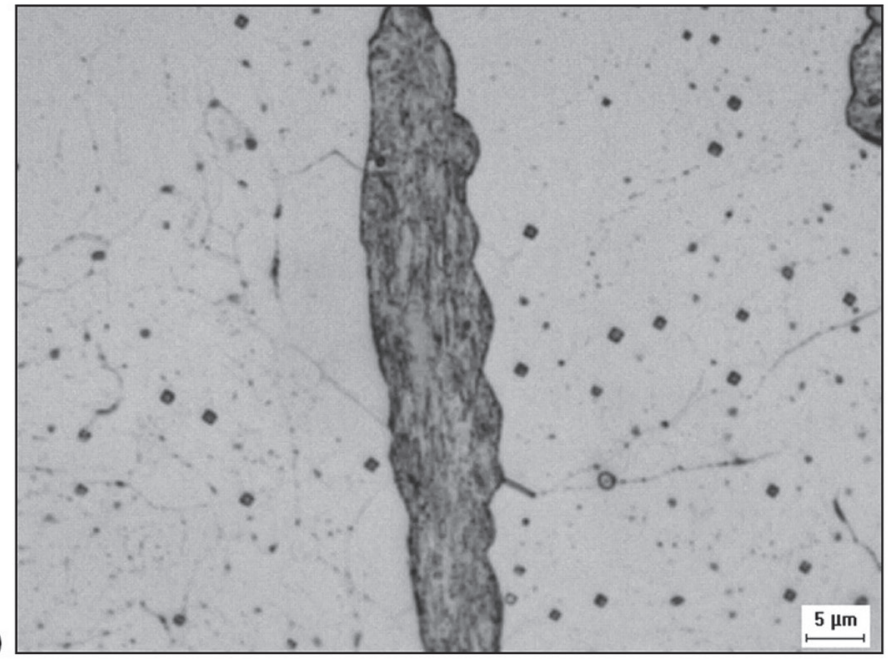

Figura 9. Microscopia ótica da martensita observada na liga E1. a) Aumento 200X. b) Aumento 1000X.

a)
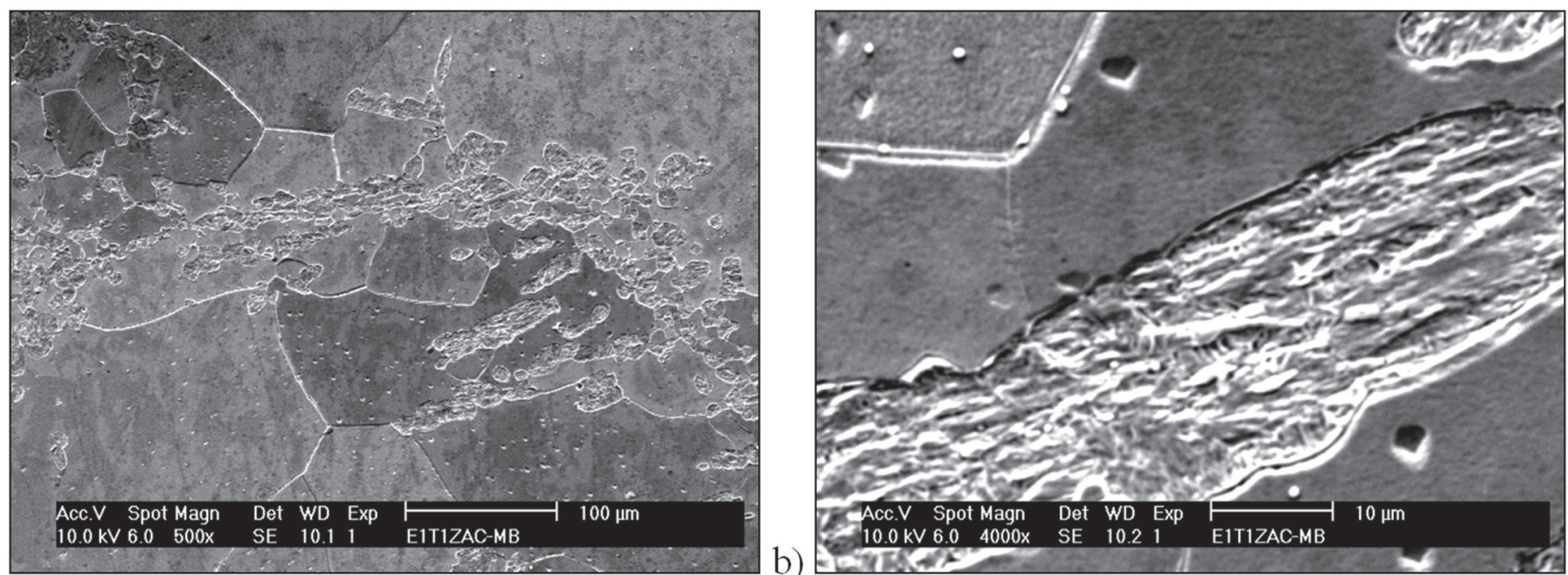

Figura 10. Microestrutura dos precipitados observados nas regiões após a solda da liga E1. a) Aumento de 500X. b) Aumento de 4000X.
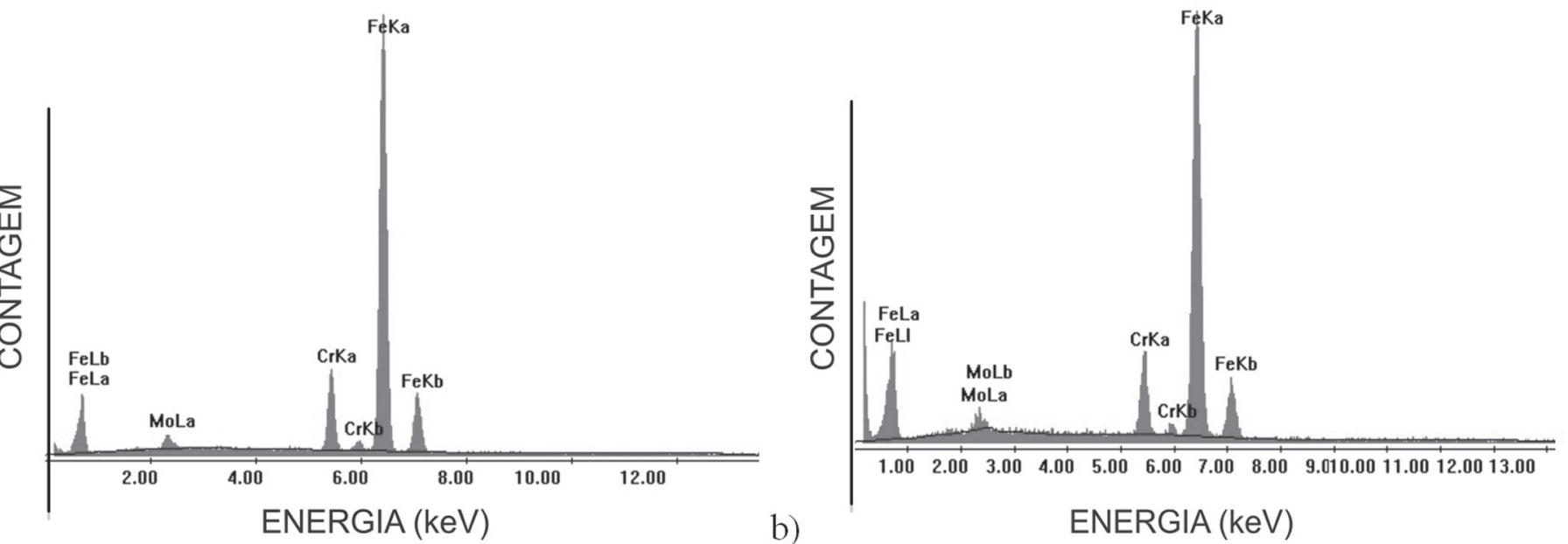

Figura 11. Análise de composição química das regiões após o metal de solda da Liga E1. a) Precipitado. b) Matriz da liga E1. 
a)
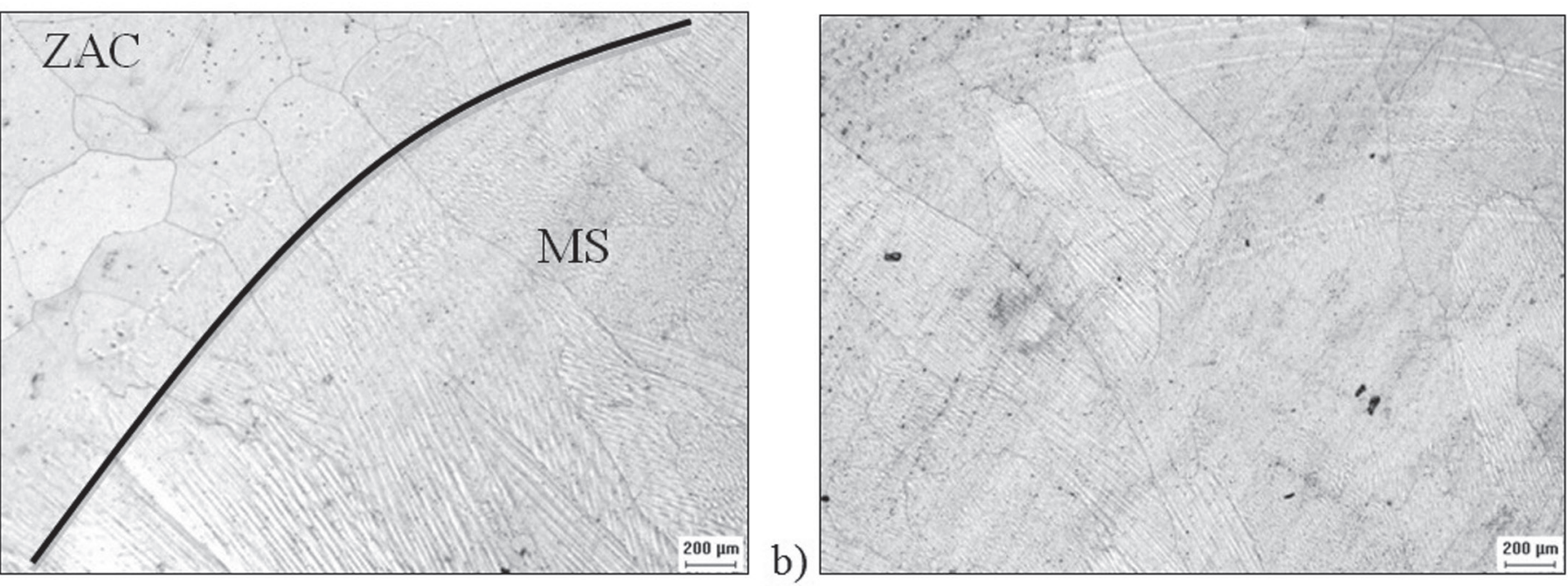

b)

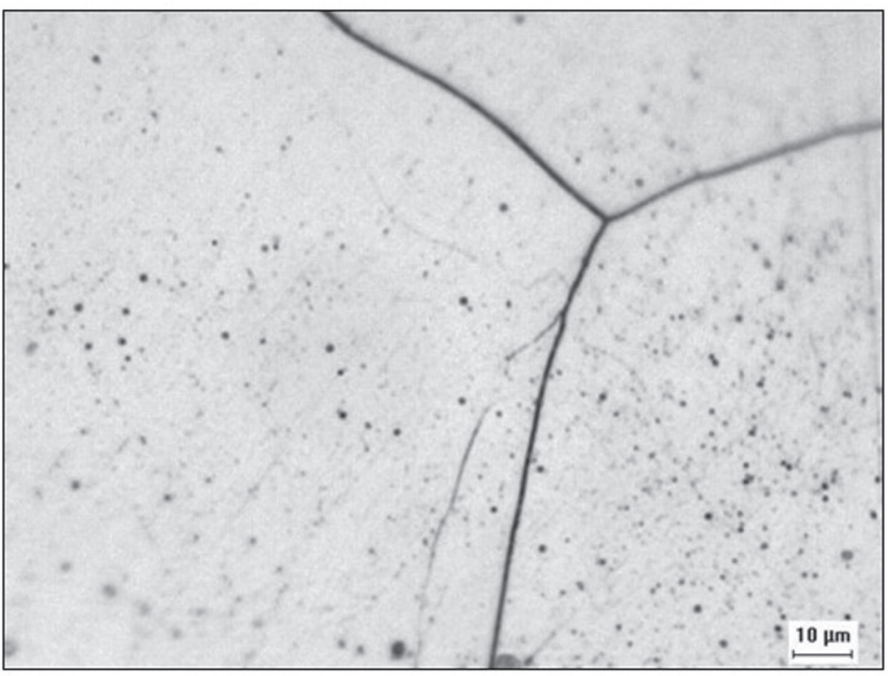

Figura 12. Micrografia da liga E2 após soldagem autógena. a) Zona afetada pelo calor da solda (ZAC), aumento 50X. b) Metal de solda (MS), aumento 50X. c) Precipitados observados nas regiões da ZAC, aumento 1000X. 

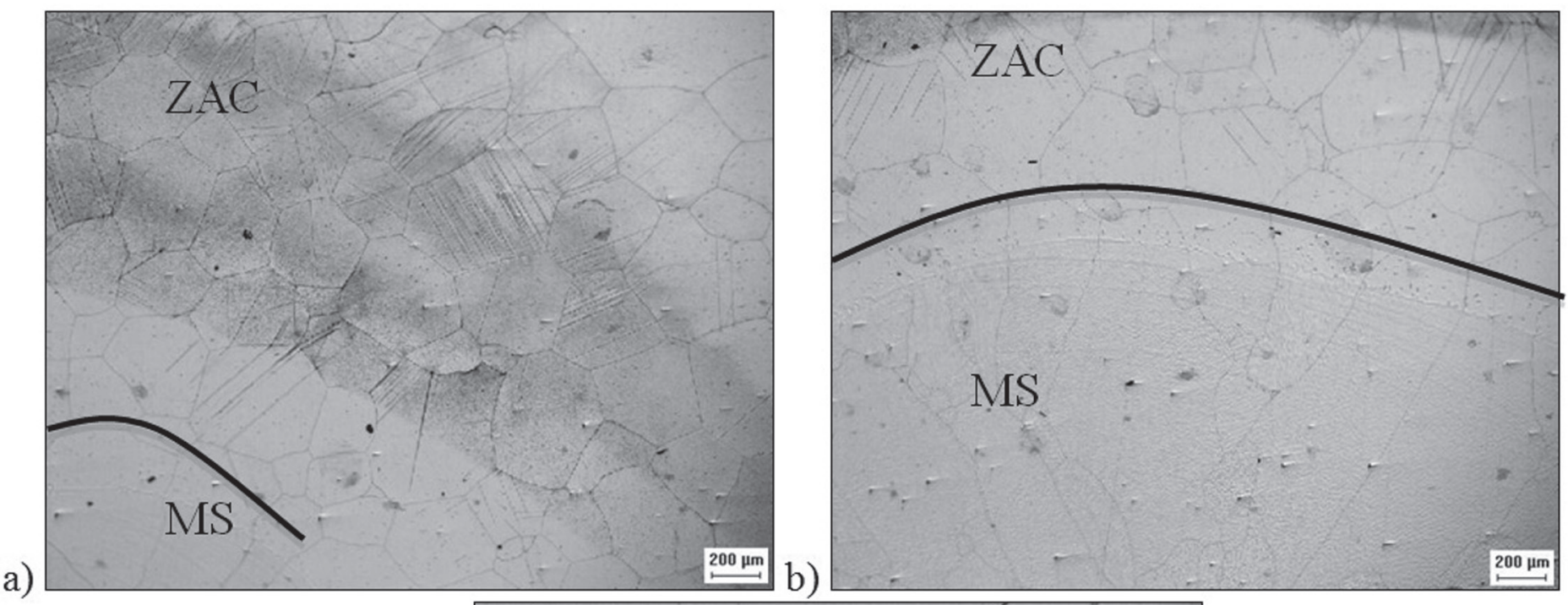

c)

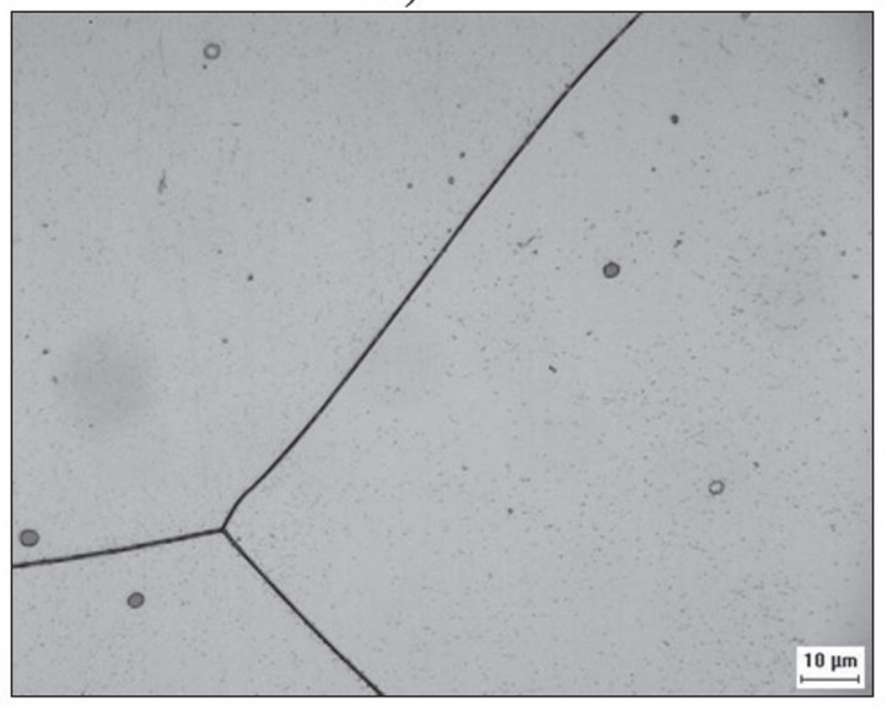

Figura 13. Micrografia da liga E3 após soldagem autógena. a) Zona afetada pelo calor da solda (ZAC), aumento 50X. b) Metal de solda (MS), aumento 50X. c) Precipitados formados nas regiões da ZAC, aumento 1000X.

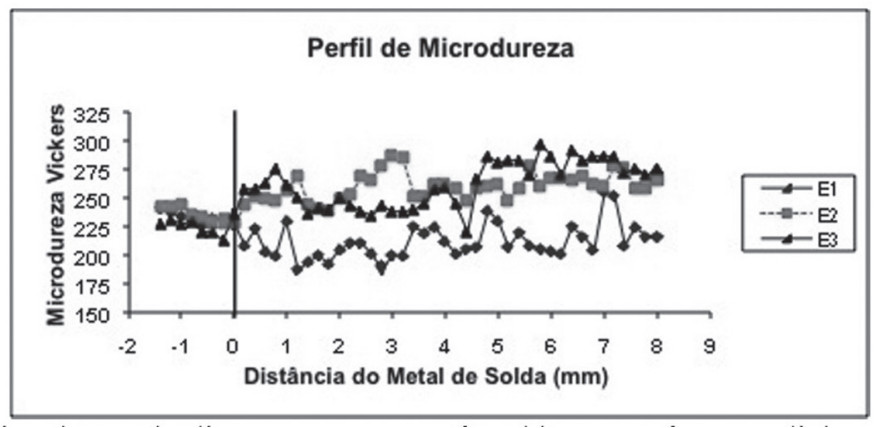

Figura 14. Perfil de microdureza das ligas E1, E2 e E3 após soldagem autógena. A linha contínua vertical indica o final da solda.

As microdurezaa Vickers das amostras E1, E2 e E3 soldadas pelo processo TIG sem adição de material estão mostradas na
Figura 14. A dureza foi medida a partir da região da solda até o metal de base. Verifica-se que a liga E3 possui o valor mais elevado de dureza, seguido da liga E2 e, por último, pela liga E1. Apesar da liga E1 ter apresentado a formação da martensita após a zona fundida, a mesma apresentou dureza inferior em relação a mesma região para as ligas E2 e E3, onde não foi verificada a presença desta fase.

Ainda que a martensita possa resultar em perda na ductilidade do material, a formação da mesma na liga E1 pode não comprometer sua aplicação, pois esta liga tem um baixo teor de carbono, favorecendo a uma martensita com dureza mais baixa.

\section{Conclusões}

Com base nos resultados apresentados neste trabalho, destacam-se as seguintes conclusões:

$\mathrm{O}$ alto teor de molibdênio presente nestas ligas favorece 
a formação de fases intermetálicas que podem prejudicar a aplicabilidade destas ligas. Contudo, foi possível obter estas ligas sem a presença destas fases prejudiciais, tanto na condição solubilizada quanto soldada.

Através do programa termodinâmico foi possível estimar as temperaturas para realização dos tratamentos de solubilização.

A análise dos diagramas de fase das ligas possibilitou a identificação das possíveis fases que podem se formar permitindo que fossem tomadas medidas para a obtenção da fase mais favorável a aplicação das ligas estudadas.

A dureza das ligas estudadas na condição solubilizada foi superior ao de ligas comerciais como a liga P9, com teor de cromo semelhante.

A liga E1 apresentou ao longo da ZAC, da solda sem adição de material, a presença de alguns precipitados, identificados como sendo martensita.

Mesmo havendo a formação de martensita na liga E1 a dureza das regiões da solda foram menores em comparação com as ligas E2 e E3, onde não foi verificada a presença da mesma, indicando que esta fase pode não prejudicar as propriedades mecânicas da liga E1.

\section{Agradecimentos}

Os autores gostariam de agradecer ao Núcleo de Pesquisa Aplicada e Inovação Industrial, ao Laboratório de Caracterização de Materiais e ao Laboratório de Engenharia de Soldagem da Universidade Federal do Ceará pela realização dos experimentos, além do CNPq, FUNCAP e CAPES e PETROBRÁS pelo suporte financeiro.

\section{Referências Bibliográficas}

[1] PÉREZ, G. J. A. Caracterização das Fases Presentes em Depósito de Níquel ER-NiCrMo-3 em Tubos de Aço de $9 \mathrm{Cr}$ 1Mo Usados em Fornos de Refinaria de Petróleo. 2005. 129p. Dissertação (Mestrado) - Faculdade de Engenharia Metalúrgica e de Materiais, Universidade Federal do Ceará, Fortaleza.

[2] CUNHA, B. R. M. da. "Soldabilidade da Nova Geração de Aços Ferríticos Cr-W Resistentes A Altas Temperaturas". Universidade Federal do Rio de Janeiro - COPPE, Rio de Janeiro - RJ, 2006.

[3] SOUZA, S. A., “Composição Química dos Aços”. São Paulo, Edgard Blücher, 1989.

[4] LAFFLER, B., "Stainless - Stainless Steel and their Properties". pp.1-44, 1999.

[5] EDSTRÖM, H. J., LJUNDBERG, L., Rost- und säurebeständige Chrom-Nickel- Stähle mit max. 0,030\% Kohlenstoff als Kontruktionsmaterial für die chemische Industrie. Werkst. u. Korrosion 15, 743-753, 1964.

[6] FONTANA, M. G. Corrosion Engineering. Cingapura: McGraw-Hill. 1986.

[7] WU, X. Q.; JING, H. M.; ZHENG, Z.M.; YAO, W.Ke. Resistance of Mo-bearing stainless-steel coating to naphthenic acid corrosion and erosion-corrosion. Corrosion Science 46, p1013-1032, 2004.

[8] SOLOMON, H.; DEVINE JR., T. Duplex stainless steel - A tale of two phase. In: Proc. Conf. Duplex Stainless Steel, 25-28, october 1982. St. Louis, USA, ASM (1983), p.693-756.

[9] NILSSON, J. O. Overview - Super duplex stainless steels. Materials Science and Technology, v.8, p.685-700, august 1992. [10] BRANDI, S. D. "Estudo da soldabilidade do aço inoxidável duplex DIN W. Nr 1.4462 (UNS S31803)". Tese (Doutorado), Escola Politécnica, Universidade de São Paulo, São Paulo, 1992. [11] PECKNER, D.; BERNSTEIN, I.M. Handbook of stainless steels, New York, McGraw-Hill, p.5-5 a 5-7, 1977.

[12] RAYNOR, G. V. RIVLIN, V. G. Phase equilíbria in iron ternary alloys. The Institute of Metals, London, p.316-32, 1985. [13] FISHER, R.M. et al, Identification of the precipitate accompanying $885^{\circ} \mathrm{C}$ embrittlement in chromium steels, Transaction AIME v. 197, pp 690-695, 1953.

[14] PARK, C. J.; ANH, M. K.; KWON, H. S. Influences of Mo substituition by $\mathrm{W}$ on the precipitation kinetics of secondary phases and the associated localized corrosion and embrittlement in $29 \% \mathrm{Cr}$ ferritic stainless steels. Materials Science and Engineering A 418, p.211-217, 2006.

[15] JOUBERT J-M, Percheron-Guégan A. J Alloys Compd 2001;317-318: 71-6

[16] JOUBERT J-M, Pommier C, Leroy E, Percheron-Guégan A. J Alloys Compd 2003;356/357:442-6.

[17] HIRATA, A.; IWAI, A.; KOYAMA, Y. Characteristic features of the Fe7Mo6-type structure in a transition-metal alloy examined using transmission electron microscopy. Physical Review B, v. 74, 054204 (2006).

[18] PADILHA, A. F.; RIOS, P.R. Decomposition of austenite in austenitic stainless steels. ISIJ International, Vol.42, No.4, p.325-337, 2002.

[19] VOORT G.F.V., JAMES H, MILLS M. K., DAVIS J.R., DESTEFANI J. D., DIETERICH D. A., CRANKOVIC G. M., FRISSELL M.J. (Eds,). ASM Handbook: "Metallography and Microstructures". Vol, 9, USA: ASM International, p. 284, 1992. [20] BHADESHIA, H.K.D.H.; HONEYCOMBE, S. R. "Steels: Microstructure and Properties". Elsevier, 2006.

[21] MUNGOLE, M.N., GADADHAR SAHOO, BHARGAVA, S., BALASUBRAMANIAM, R. "Recrystalised grain morphology in 9Cr 1Mo ferritic steel". Materials Science Engineering A 476, p. 140-145, 2008.

[22] SILVA, C. C., NETO, J.C.A, SANT'ANA, H. B., FARIAS, J. P. "Alterações Microestruturais na ZAC do aço inoxidável ferrítico 410S - Efeitos sobre a resistência à corrosão". Soldagem \& Inspeção 11, 2006. 